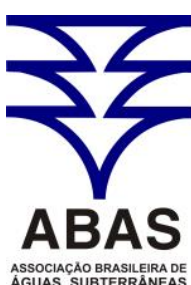

ASSOCIACAO BRASLLERADE
AGUAS SUBTERANEAS www.abas.org

\title{
CARACTERIZAÇÃO GEOMÉTRICA E HIDRÁULICA DO SISTEMA AQUÍFERO URUCUIA MERIDIONAL COM BASE EM TESTES DE AQUÍFERO E LEVANTAMENTOS GEOFÍSICOS ELÉTRICOS
}

\author{
HYDRAULIC AND GEOMETRIC CHARACTERIZATION OF THE \\ SOUTHERN URUCUIA AQUIFER SYSTEM BASED ON AQUIFER TESTS \\ AND ELECTRIC GEOPHYSICAL SURVEY
}

\author{
Natanael da Silva Barbosa ${ }^{1}$, Luiz Rogério Bastos Leal ${ }^{2}$, Natali da Silva Barbosa ${ }^{3}$, José \\ de Castro Mello ${ }^{4}$, Cristovaldo Bispo dos Santos ${ }^{5}$, Olivar Antônio Lima de Lima ${ }^{6}$
}

Artigo recebido em: 31/01/2014 e aceito para publicação em: 27/07/2014.

\begin{abstract}
Geophysical surveys obtained through 65 vertical electrical soundings integrated to the results of aquifer tests supported a hydrodynamic modeling and regional structuring of the Southern Urucuia Aquifer System in Formoso and Arrojado watersheds. The aquifer is formed predominantly by sandstone layers with different resistivity, with more conductive levels in its lower portion, what is represented by Bambuí Group lithologies. The saturated thickness increases from east to west, reaching more than $500 \mathrm{~m}$ in Serra Geral border. The groundwater flows from west to east, except in the far west where there is a groundwater divisor in the hydrogeological basin. The hydrodynamic parameters reveal two kinds of aquifers: a lower one, classified as confined type and represented by Posse Formation, with high hydrogeological potential and flows higher than $300 \mathrm{~m}^{3} / \mathrm{h}$, utilized predominantly for irrigation. Its transmissivity ( T) varies from $10^{-1}$ to $10^{-3} \mathrm{~m}^{2} / \mathrm{s}$, its hydraulic conductivity (K) between $10^{-4}$ to $10^{-6} \mathrm{~m} / \mathrm{s}$, and storage coefficient (S) of the order of $10^{-4}$. The superior one is classified as a non-confined type, and it is represented by Serra das Araras Formation with a hydrogeological potential varying from low to medium and flows lower than $15 \mathrm{~m}^{3} / \mathrm{h}$, mainly utilized for domestic supplying. It displays T varying from $10^{-4}$ to $10^{-5} \mathrm{~m}^{2} / \mathrm{s}$, $\mathrm{K}$ between $10^{-6}$ to $10^{-7} \mathrm{~m} / \mathrm{s}$, and $\mathrm{S}$ of the order of $10^{-2}$ to $10^{-3}$. Its base flow maintains the drainage network pereniallity in the rainfall recession. The silicified and fractured levels of Serra das Araras Formation behave as a semipermeable layer confining the aquifer system in depth.
\end{abstract}

Keywords: Vertical electrical sounding. Aquifer tests. Hydrodynamic modeling. Hydrodynamic parameters. Silicified levels.

Resumo: Levantamentos geofísicos executados através de 65 sondagens elétricas verticais integradas a testes de aquífero deram suporte a uma modelagem hidrodinâmica e estruturação regional do Sistema Aquífero Urucuia Meridional, nas bacias hidrográficas dos rios Formoso e Arrojado. O aquífero forma-se predominantemente por camadas de arenitos com diferentes resistividades, apresentando em sua porção inferior níveis mais condutivos, representados pelas litologias do Grupo Bambuí. A espessura saturada aumenta de leste para oeste, alcançando mais de 500 m na borda da Serra Geral. O fluxo da água subterrânea é de oeste para leste, exceto no extremo oeste onde ocorre um divisor de água subterrânea na bacia hidrogeológica. Os parâmetros hidrodinâmicos revelam dois tipos de aquíferos: o inferior do tipo confinado, representado pela Formação Posse, com alto potencial hidrogeológico e vazões maiores que $300 \mathrm{~m}^{3} / \mathrm{h}$, utilizado predominantemente para irrigação. Possui transmissividade (T) variando de $10^{-1}$ a $10^{-3} \mathrm{~m}^{2} / \mathrm{s}$, condutividade hidráulica (K) entre $10^{-4}$ a $10^{-6} \mathrm{~m} / \mathrm{s}$ e coeficiente de armazenamento (S) da ordem de $10^{-4}$. Já o superior, do tipo não-confinado, é representado pela Formação Serra das Araras, com potencial hidrogeológico variando de baixo a médio e vazões menores que $15 \mathrm{~m}^{3} / \mathrm{h}$, utilizado predominantemente para abastecimento doméstico. Apresenta T variando de $10^{-4}$ a $10^{-5} \mathrm{~m}^{2} / \mathrm{s}$, K entre $10^{-6}$ a $10^{-7} \mathrm{~m} / \mathrm{s}$ e S da ordem de $10^{-2}$ a $10^{-3}$. Seu fluxo de base mantém a perenidade da rede de drenagem durante a recessão das chuvas. Os níveis silicificados e fraturados da Formação Serra das Araras comportam-se como uma camada semipermeável, confinando o sistema aquífero em profundidade.

Palavras-chave: Sondagens elétricas verticais. Testes de aquífero. Modelagem hidrodinâmica. Parâmetros hidrodinâmicos. Níveis silicificados.

\footnotetext{
${ }^{1}$ Universidade Federal do Oeste da Bahia/Universidade Federal da Bahia (natanael_barbosa@ufob.edu.br).

${ }^{2}$ Instituto de Geociências/Universidade Federal da Bahia (lrogerio@ufba.br).

3 Instituto de Geociências/Universidade de São Paulo (natali@usp.br).

${ }^{4}$ Companhia de Engenharia Ambiental da Bahia (castromello@yahoo.com.br).

${ }^{5}$ Instituto de Geociências/Universidade Federal da Bahia (bispo@ufba.br).

${ }^{6}$ Instituto de Geociências/Universidade Federal da Bahia (olivar@cpgg.ufba.br).
} 


\section{INTRODUÇÃO}

O Sistema Aquífero Urucuia (SAU) (GASPAR, 2006) representa um dos mais importantes mananciais de água subterrânea do Brasil, distribuindo-se por seis estados brasileiros (Bahia, Tocantins, Minas Gerais, Piauí, Maranhão e Goiás), com área de aproximadamente $120.000 \mathrm{~km}^{2}$. A espessura do pacote sedimentar pode atingir valores máximos acima de $600 \mathrm{~m}$ (GASPAR et al., 2012). Este sistema é responsável pela perenidade de vários afluentes nas bacias hidrográficas dos rios São Francisco e Tocantins, durante todo o período de estiagem, entre os meses de abril e outubro, sendo responsável por cerca de $90 \%$ da descarga de base dos rios da região oeste da Bahia (PIMENTEL et al., 2000). Desse modo, estima-se que uma possível utilização, em larga escala, das águas subterrâneas do SAU interfira diretamente no volume de água que escoa superficialmente nos rios das bacias hidrográficas supracitadas, causando modificações geo-ambientais significativas (AQUINO et al., 2003).

Nos últimos 30 anos, a região oeste do estado da Bahia vem experimentando um acelerado processo de expansão de atividades agroindustriais e crescimento urbano, se tornando um dos importantes polos para o desenvolvimento do país, destacando-se a implantação de culturas irrigadas (e.g. café, milho, arroz, algodão, frutas, etc). Dessa forma, a demanda por água para irrigação tem sido crescente a ponto de alguns mananciais superficiais (e.g. rio das Fêmeas, rio Grande) estarem, desde o ano de 2003, com a sua disponibilidade hídrica para outorga esgotada, fato que tem levado os segmentos produtivos a intensificar a explotação e uso das águas subterrâneas através da perfuração de poços profundos (SCHUSTER et al., 2002).

Este trabalho tem como objetivo a caracterização geométrica e hidráulica do segmento meridional do SAU, contribuindo para o entendimento dos mecanismos que atuam na dinâmica de fluxo do aquífero e de suas interconexões com a rede de drenagem superficial nas bacias hidrográficas dos rios Formoso e Arrojado, a partir da determinação dos parâmetros hidrodinâmicos do aquífero, ou seja, a transmissividade $(T)$, a condutividade hidráulica $(K)$ e o coeficiente de armazenamento $(S)$ e de levantamentos geofísicos elétricos. Os resultados desta pesquisa deverão contribuir para o aprimoramento das políticas de gestão e uso das águas na região oeste da Bahia.

\section{MATERIAIS E MÉTODOS}

Os trabalhos de campo envolveram a obtenção de informações e dados sobre o SAU, levantamentos geofísicos elétricos e realização de testes de aquífero em poços tubulares existentes. Após o cadastramento e nivelamento topográfico dos poços selecionados para compor uma rede de monitoramento com auxílio de um GPS geodésico, foram executados medidas da profundidade do nível freático em 34 poços selecionados em períodos chuvosos e de estiagem.

Os parâmetros hidrodinâmicos foram obtidos através da realização de testes de aquífero em poços parcialmente penetrantes e préselecionados nas fazendas COBA (Companhia do Oeste da Bahia) e Buriti, localizados nas bacias hidrográficas do rio Formoso e Arrojado, respectivamente. $\mathrm{O}$ teste na fazenda COBA teve duração de 24 horas, com bombeamento do poço PT-33 (232 $\mathrm{m}$ de profundidade) e acompanhamento do rebaixamento e pressão atmosférica no piezômetro PO-33 (70 m de profundidade), situado a $22 \mathrm{~m}$ do poço PT-33 e posterior recuperação do nível dinâmico com duração de 24 horas. Já o teste na fazenda Buriti envolveu 21 horas de bombeamento do poço PT-127 (100 m de profundidade), com observação da evolução dos rebaixamentos dos níveis d'água e da pressão atmosférica no piezômetro PO-127 (70 m de profundidade), situado a uma distância de $22 \mathrm{~m}$ do poço PT-127 e recuperação do nível dinâmico com duração de 3 horas (Figura 1). Na prática, a impossibilidade de interrompimento do abastecimento de água na fazenda Buriti por um período de tempo necessário para que o poço PT-127 (em regime de operação) e o PO-127 voltassem a uma condição de equilíbrio, dificultou as operações em campo.

A vazão de bombeamento registrada pelo método de ultrassom no teste da fazenda COBA foi de $399 \mathrm{~m}^{3} / \mathrm{h}$, enquanto na fazenda Buriti foi de $10,8 \mathrm{~m}^{3} / \mathrm{h}$ obtida pelo método volumétrico. A evolução dos rebaixamentos dos níveis d'água e da pressão atmosférica foi registrada através do uso de sensores eletrônicos instalados nos poços de bombeamento e piezômetros. O tratamento dos dados dos testes de aquífero foi realizado através do software AquiferTest 4.0 da Waterloo Hydrogeologic Inc., utilizando os métodos de Theis (1935) e Neuman (1975), para aquíferos confinado e livre, respectivamente.

Os levantamentos geofísicos foram executados através de 65 sondagens elétricas verticais 
(SEV) de resistividade, executadas com o arranjo de eletrodos Schlumberger expandidos até um espaçamento $\mathrm{AB} / 2$ máximo de $1.000 \mathrm{~m}$, utilizando os sistemas SYSCAL R-2 e SYSCAL-PRO, da Iris Instruments. Os dados obtidos foram invertidos utilizando-se modelos unidimensionais atra- vés dos softwares RES1D da Geotomo Softwares, para compor os modelos estruturais iniciais a serem submetidos à inversão e RESIST 1.0 para efetuar a inversão não-linear por mínimos quadrados (LIMA, 2007; KOEFOED, 1979; VOZOFF, 1958).
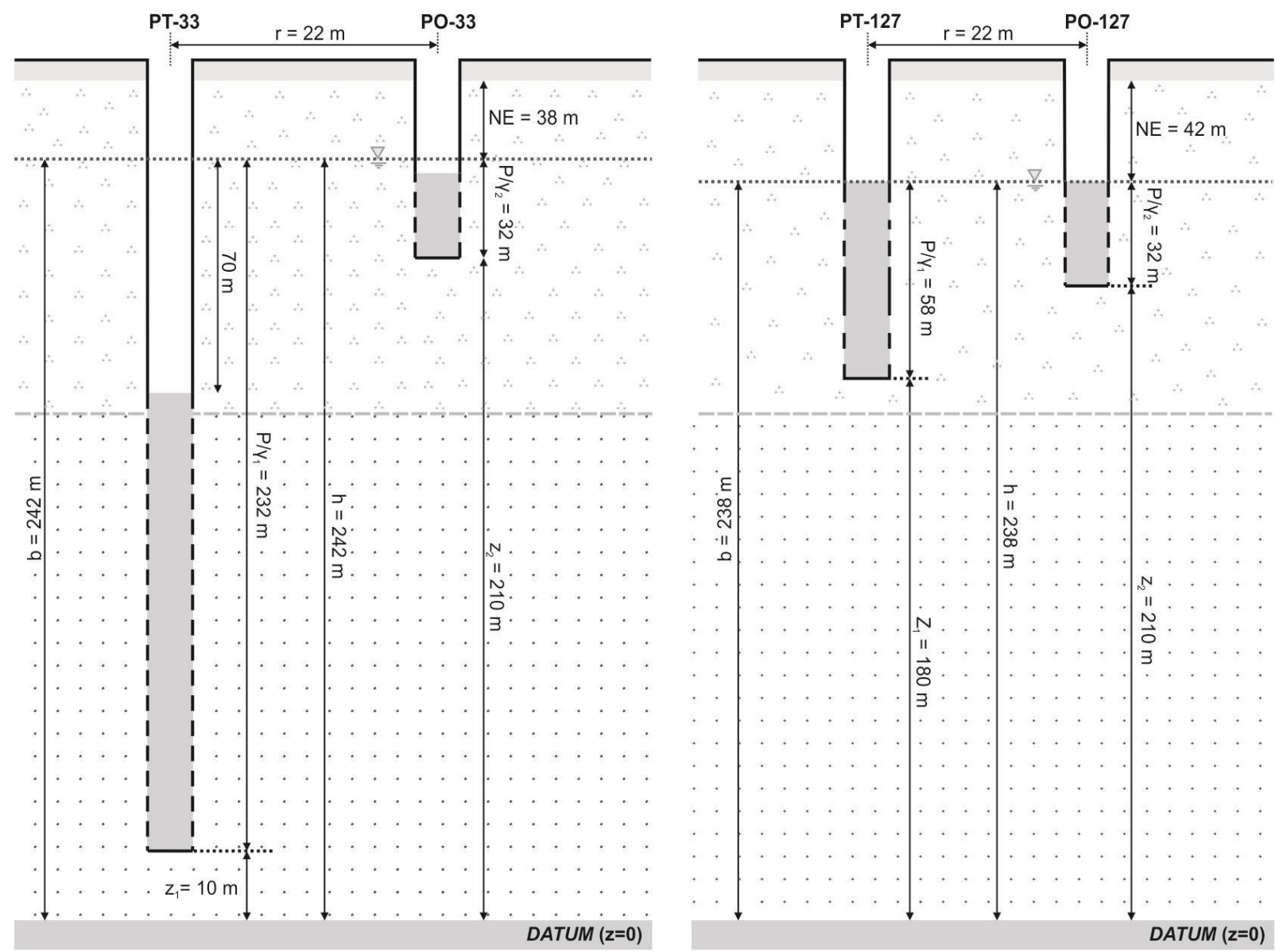

I I Seções filtrantes

PT-33= poço de bombeamento (Fazenda COBA) PO-33= poço de observação (Fazenda COBA)

PT-127= poço de bombeamento (Fazenda Buriti) PO-127= poço de observação (Fazenda Buriti) $z=$ altitude ou cota do ponto (carga de elevação) $\mathrm{b}=$ espessura do aqüífero

$\mathrm{h}=$ carga hidráulica

$\mathrm{P} / \mathrm{Y}=$ metros de coluna de água acima do ponto (carga de pressão)

$r=$ distância entre o poço de bombeamento e o poço de observação $\mathrm{NE}=$ nível estático

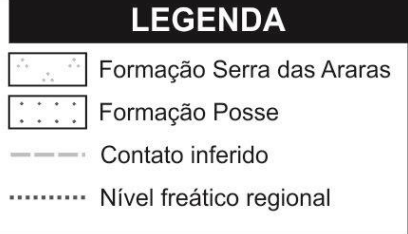
LEGENDA

Figura 1 - Configuração dos poços utilizados nos testes de aquíferos realizados nas fazendas COBA e Buriti, ilustrando os parâmetros de penetração em relação à espessura do aquífero

Figure 1 - Well configuration used in aquifer tests in COBA and Buriti farms illustrating the penetration parameters in relation to aquifer thickness

\section{CONTEXTO GEOLÓGICO E HIDROGEOLÓGICO}

O SAU (GASPAR, 2006; GASPAR \& CAMPOS, 2007) constitui uma associação de unidades aquíferas que ocorrem no domínio da sequência das rochas siliciclásticas do Grupo Urucuia, formadas a partir de sedimentação neocretácea em ambientes eólico e fluvial, associados às coberturas fanerozoicas do Cráton do São
Francisco denominada de bacia intracontinental Sanfranciscana (SGARBI, 1989). Duas unidades hidro-litoestratigráficas principais são reconhecidas, basal e superior denominadas de Formação Posse e Serra das Araras, respectivamente, depositadas, na área de estudo, sobre o sistema cárstico-fissural, representado pelas sequências de ro- 
chas pelítico-carbonáticas neoproterozoicas do Grupo Bambuí e terrenos granito-gnáissicos de idade Arqueno/Paleoproterozoica do complexo gnáissico-migmatítico de Correntina (CAMPOS \& DARDENNE, 1997a, b) (Figura 2). O contato entre as Formações Posse e Serra das Araras é abrupto, através de uma superfície erosiva, considerada por Spigolon \& Alvarenga (2002) como uma megassuperfície dentro do ambiente deposicional do Grupo Urucuia.

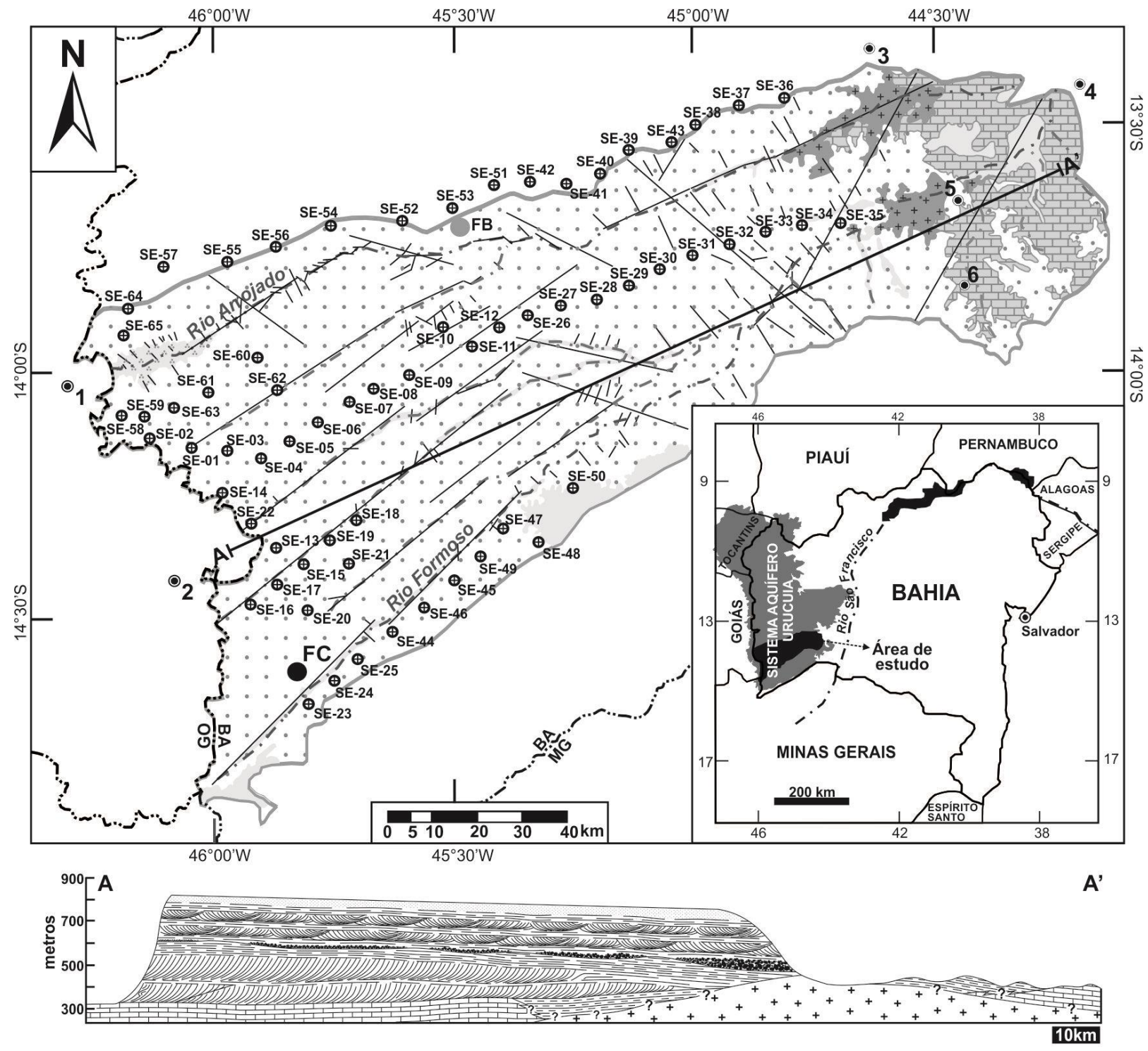

\begin{tabular}{|c|c|}
\hline LEGENDA & CONVENÇÕES \\
\hline 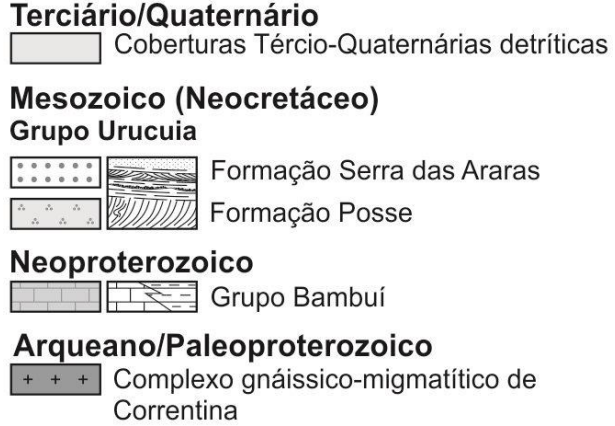 & $\begin{array}{l}\text { Lineamento estrutural } \\
- \text { Rios } \\
\oplus \quad \text { Centro de sondagem elétrica vertical } \\
-8 A-\text { Limite inter-estadual } \\
\text { Localidades } \\
\text { Sedes municipais } \\
\text { Fazenda COBA (Companhia do Oeste da Bahia) (FC) } \\
\text { Fazenda Buriti (FB) } \\
\text { 1- Posse (GO); 2- Mambai (GO); 3- Correntina (BA); 4- Sta. Maria da } \\
\text { Vitória (BA); 5- São Félix Coribe (BA); 6- Jaborandi (BA); 7- Coribe (BA) }\end{array}$ \\
\hline
\end{tabular}

Figura 2 - Mapa geológico da área de estudo, destacando a localização dos centros de sondagens elétricas verticais e poços onde foram realizados os testes de aquífero

Figure 2 - Geological map of the studied area highlighting the location of centers of vertical electrical sounding and wells where the aquifer tests were performed 
A Fm. Posse é constituída essencialmente por arenitos róseos a avermelhados, granulometria fina a média, grãos subarredondados a arredondados, boa esfericidade e bem selecionados, com estratificações cruzadas de grande porte. Normalmente, são friáveis e localmente silicificados nas porções do topo, próximo ao contato com a Fm. Serra das Araras. Apresenta espessura aflorante de até $120 \mathrm{~m}$, na região de Posse-GO. Já a Fm. Serra das Araras é constituída por ciclos de sedimentação superpostos e composta por conglomerados, arenitos e siltitos, intercalados em bancos plano-paralelos, com espessuras de até 2 m. Na base da sequência, os níveis conglomeráticos (de até $50 \mathrm{~cm}$ ) são avermelhados, com seixos de quartzo, quartzitos, arenitos da própria sequência e feldspatos caolinizados. Os arenitos predominam, sendo polimodais, silicificados, vermelhos e com níveis amarelados. Na base destes, estratificações cruzadas acanaladas de pequeno porte são observadas, modificando-se em direção ao topo para estratos plano-paralelos. Na porção superior ocorrem horizontes pelíticos avermelhados de até $50 \mathrm{~cm}$, que se dispõe brechados e com gretas de contração. Essa unidade, normalmente, dispõe-se com intensa cimentação por sílica e óxido de ferro. Apresenta espessuras totais variáveis, podendo alcançar até $150 \mathrm{~m}$ (BORGES ET AL., 1992; CAMPOS \& DARDENNE, 1997A; CAMPOS \& DARDENNE 1999; SPIGOLON \& ALVARENGA, 2002).

A geometria e arranjo lito-estrutural das unidades aquíferas, os levantamentos gravimétricos e eletromagnéticos regionais e as investigações de resistividade e polarização elétrica induzida indicam variações de espessura desde alguns metros, podendo atingir valores da ordem de 600 $\mathrm{m}$ no depocentro da bacia (AMORIM JR. \& LIMA, 2007; BONFIM \& GOMES, 2004, GASPAR ET AL., 2012; TSCHIEDEL, 2004). A presença de zonas silicificadas e fraturadas, seu posicionamento geográfico e espacial e as variações hidrodinâmicas das unidades aquíferas, possibilitam a diferenciação do SAU em quatro subtipos aquíferos, denominados: livre regional, confinado, livre com níveis estáticos profundos e suspenso local (GASPAR \& CAMPOS, 2007). No SAU meridional são reconhecidos os subtipos livre regional e confinado, associados às formações Serra das Araras e Posse, respectivamente, além do livre com níveis estáticos profundos posicionados no extremo oeste da área. Os aquíferos suspensos apresentam distribuição local, em função da presença de níveis silicificados rasos e de limitada extensão que retardam a drenagem vertical da água.

Os testes de aquífero realizados em diferentes posições geográficas do SAU, nos dois principais tipos de aquíferos, revelam altos valores de transmissividade $\left(10^{-2}-10^{-3} \mathrm{~m}^{2} / \mathrm{s}\right)$ e coeficiente de armazenamento da ordem de $10^{-4}$ para o aquífero confinado (NASCIMENTO, 2003; SCHUSTER ET AL., 2002; SCHUSTER ET AL., 2003; GASPAR \& CAMPOS, 2007), com obtenção de grandes vazões, pequenos rebaixamentos observados nos poços e raios de influência extensos (acima de $2.500 \mathrm{~m}$ ), acarretando em interferências entre os poços e desses com os cursos de águas superficiais nas épocas de estresse hídrico (meses de maio a outubro). Já o sistema livre regional apresenta menores valores de transmissividade $\left(10^{-4}-10^{-5} \mathrm{~m}^{2} / \mathrm{s}\right)$ e coeficiente de armazenamento entre $10^{-2}$ e $10^{-3}$ (Tabela 1). Dessa forma, as variações observadas na transmissividade ocorrem provavelmente devido a modificações na espessura saturada e/ou mudanças na condutividade hidráulica do aquífero.

A análise do mapa de fluxo de água subterrânea mostra três importantes aspectos: (i) as principais drenagens da região, dispõe-se num padrão paralelo de direção SSW-NNE, são rios consequentes e perenes cujas descargas de base constituem em grande parte ao volume de água restituído pelo SAU; (ii) o fluxo das águas subterrâneas ocorre preferencialmente de SSW para NNE e; (iii) uma compartimentação do SAU por meio de um divisor de água subterrânea, de direção aproximada N-S, dividindo o escoamento subterrâneo a leste em direção à bacia do rio São Francisco e a oeste em direção à bacia do rio Tocantins (Figura 3).

Tabela 1 - Sumário dos parâmetros hidrodinâmicos regionais em sub-bacias hidrográficas do Sistema Aquífero Urucuia

(continua)

Table 1 - Summary of regional hydrodynamic parameters in Urucuia Aquifer System watersheds

\begin{tabular}{|c|c|c|c|c|c|c|c|}
\hline Localização & $\begin{array}{l}\text { Unidade } \\
\text { Aquífera } \\
\end{array}$ & $\begin{array}{l}\mathrm{Q} / \mathrm{s} \\
\left(\mathrm{m}^{3} / \mathrm{h} / \mathrm{m}\right)\end{array}$ & $\begin{array}{l}T \\
\left(\mathrm{~m}^{2} / \mathrm{s}\right) \\
\end{array}$ & $\begin{array}{l}\mathrm{K} \\
(\mathrm{m} / \mathrm{s}) \\
\end{array}$ & $\mathbf{S}^{*}$ & Método & Ref. \\
\hline \multirow[b]{2}{*}{ Bacia rio do Cachorro } & \multirow{4}{*}{ Fm. Posse } & 21,60 & $1,6 \times 10^{-2}$ & $1,0 \times 10^{-4}$ & $2,6 \times 10^{-4}$ & Cooper/Jacob & \\
\hline & & - & $1,6 \times 10^{-2}$ & $1,1 \times 10^{-4}$ & $1,5 \times 10^{-4}$ & $\begin{array}{l}\text { Cooper/Jacob } \\
\text { (Recup.) }\end{array}$ & 1 \\
\hline \multirow[t]{2}{*}{ Bacia rio de Janeiro } & & \multirow[t]{2}{*}{ - } & $1,6 \times 10^{-2}$ & \multirow[t]{2}{*}{-} & $2,7 \times 10^{-4}$ & \multirow[t]{2}{*}{-} & \multirow[t]{2}{*}{2} \\
\hline & & & $2,0 \times 10^{-2}$ & & $2,6 \times 10^{-4}$ & & \\
\hline
\end{tabular}


Tabela 1 - Sumário dos parâmetros hidrodinâmicos regionais em sub-bacias hidrográficas do Sistema Aquífero Urucuia

Table 1 - Summary of regional hydrodynamic parameters in Urucuia Aquifer System watersheds

\begin{tabular}{|c|c|c|c|c|c|c|c|}
\hline Localização & $\begin{array}{l}\text { Unidade } \\
\text { Aquífera }\end{array}$ & $\begin{array}{l}\mathbf{Q} / \mathbf{s} \\
\left(\mathrm{m}^{3} / \mathrm{h} / \mathrm{m}\right)\end{array}$ & $\begin{array}{l}T \\
\left(m^{2} / s\right)\end{array}$ & $\begin{array}{l}\mathrm{K} \\
(\mathrm{m} / \mathrm{s})\end{array}$ & $\mathbf{S}^{\star}$ & Método & Ref. \\
\hline \multirow{3}{*}{ Bacia rio das Fêmeas } & \multirow{6}{*}{ Fm. Posse } & 70,40 & $1,5 \times 10^{-2}$ & $6,7 \times 10^{-5}$ & $7,5 \times 10^{-4}$ & \multirow{3}{*}{ Neuman } & \multirow{3}{*}{3} \\
\hline & & 99,20 & $1,7 \times 10^{-2}$ & $6,9 \times 10^{-5}$ & $3,0 \times 10^{-4}$ & & \\
\hline & & 227,70 & $1,7 \times 10^{-2}$ & $4,4 \times 10^{-4}$ & $5,9 \times 10^{-4}$ & & \\
\hline \multirow{3}{*}{$\begin{array}{l}\text { Bacias rio de Janeiro e } \\
\text { rio das Fêmeas }\end{array}$} & & 9,71 & $8,9 \times 10^{-3}$ & $2,5 \times 10^{-5}$ & $1,0 \times 10^{-4}$ & \multirow{3}{*}{ Cooper/Jacob } & \multirow{3}{*}{4} \\
\hline & & 12,35 & $2,5 \times 10^{-2}$ & $6,4 \times 10^{-5}$ & $1,4 \times 10^{-4}$ & & \\
\hline & & 15,18 & $1,9 \times 10^{-2}$ & $3,8 \times 10^{-5}$ & $1,8 \times 10^{-4}$ & & \\
\hline \multirow{4}{*}{ Bacia rio Formoso } & \multirow{4}{*}{$\begin{array}{l}\text { Fm. Serra } \\
\text { das Araras }\end{array}$} & 0,46 & $4,9 \times 10^{-5}$ & $2,5 \times 10^{-7}$ & - & \multirow{4}{*}{ Neuman } & \multirow{4}{*}{5} \\
\hline & & 2,70 & $2,8 \times 10^{-4}$ & $1,4 \times 10^{-6}$ & - & & \\
\hline & & - & $8,0 \times 10^{-5}$ & $4,0 \times 10^{-7}$ & - & & \\
\hline & & - & $1,6 \times 10^{-4}$ & $7,9 \times 10^{-7}$ & - & & \\
\hline
\end{tabular}

Fonte: 1- Schuster et al., 2002; 2- Schuster et al., 2003; 3- Nascimento 2003, 4- Gaspar \& Campos (2007), 5- Gaspar (2006). *Coeficiente de armazenamento específico $\left(\mathrm{S}_{\mathrm{s}}\right)$ no caso do aquífero confinado da Fm. Posse e porosidade efetiva $\left(\mathrm{S}_{\mathrm{y}}\right)$ no caso do aquífero livre regional da Fm. Serra das Araras. Q/s, capacidade específica; T, transmissividade; K, condutividade hidráulica; S, coeficiente de armazenamento; Recup, Recuperação; Ref, Referência.
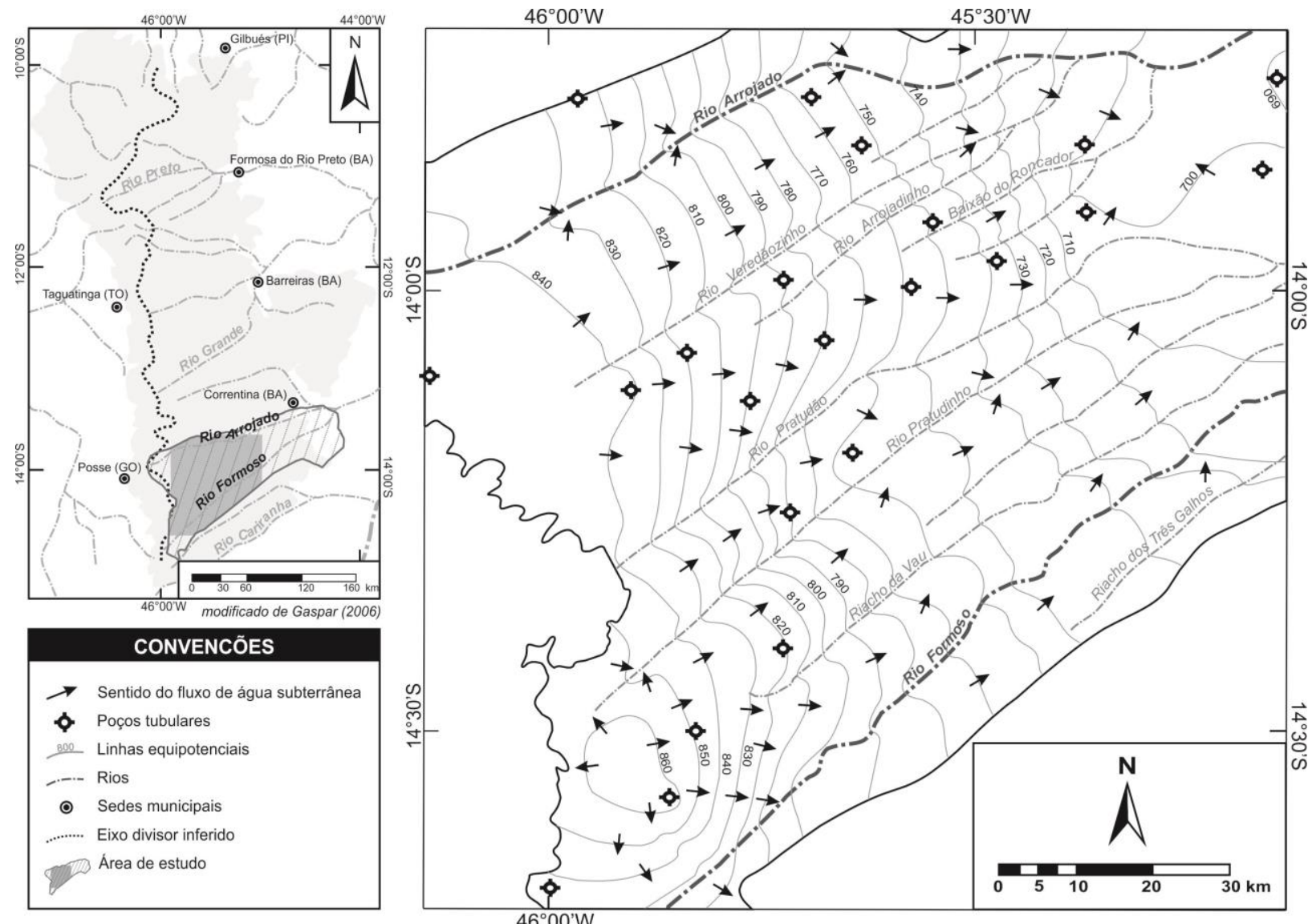

Figura 3 - Mapa potenciométrico e de fluxo de água subterrânea no segmento oeste das bacias hidrográficas dos rios Formoso e Arrojado

Figure 3 - Potentiometric and groundwater flow map in Formoso and Arrojado watersheds western segment

\section{RESULTADOS E DISCUSSÕES}

\section{Caracterização geofísica}

O conhecimento da profundidade e espessura das unidades geológicas é de grande importância nos estudos que envolvem a elaboração de um modelo hidrogeológico conceitual e com- põem, em geral, sua dimensão vertical (ANDERSON \& WOESSNER, 1992). Esses parâmetros podem ser obtidos de maneira direta através dos perfis geológicos de poços, que nem sempre apre- 
sentam essas informações com o grau de precisão exigido para os estudos hidrogeológicos e, de modo indireto, utilizando-se de métodos geofísicos, cuja aplicação depende do conhecimento da geologia local.

$\mathrm{Na}$ área estudada, os poços possuem uma distribuição irregular, suas profundidades em geral, não atravessam toda a espessura do aquífero e a maioria dos dados de perfis litológicos não é confiável. Dessa forma, foram realizadas SEV's de resistividade em 65 pontos selecionados, de forma a complementar as informações dos perfis de poços ou produzir dados onde inexistem poços. A maioria das SEV's localiza-se ao longo das rodovias principais e secundárias, numa configuração espacial suficiente para representar os resultados em termos de quatro seções geoelétricas (Figura 4). As sondagens SE-23 e SE-53 foram utilizadas para estimar as espessuras do sistema aquífero nas vizinhanças dos poços onde foram realizados os testes de aquífero nas fazendas $\mathrm{CO}$ BA e Buriti, respectivamente, de forma a reduzir a ambiguidade da interpretação geoelétrica final.

As SEV's efetuadas apresentam comportamento regular e suave, compatível com modelos estratificados de camadas sub-horizontais. Todavia, algumas curvas apresentaram fortes deslocamentos de ramos quando da mudança dos eletrodos de potencial $\mathrm{M}$ e N, devido a variações laterais na resistência de contato com os solos subsaturados em água, necessitando, para tanto, um processamento de redução, de maneira a deslocar numericamente os ramos afetados por valores constantes.

Curvas geoelétricas teóricas foram ajustadas às medidas de resistividades aparentes até alcançarem erros quadráticos médios inferiores a $2 \%$. Durante o processo de inversão a profundidade do nível freático foi fixada e as resistividades e profundidades das camadas foram obtidas (LIMA, 2007).

A maioria das curvas de resistividade apresenta uma forma de dupla de colinas com uma depressão central, refletindo as variações litológicas do Grupo Urucuia (Figura 5). Este padrão é corroborado por trabalhos anteriores realizados na porção central do SAU, nas bacias hidrográficas do rio das Fêmeas e do Cachorro (e.g. AMORIM JÚNIOR \& LIMA 2007; LIMA, 2000). Os altos valores de resistividade encontrados indicam tratar-se predominantemente de arenitos com as colinas correspondendo a pacotes arenosos mais limpos, representado provavelmente pela zona não-saturada e níveis silicificados, respectivamente. A depressão central se deve a uma redução na resistividade do aquífero, associ- ada a intercalações argilosas ou variações locais de porosidade no aquífero livre da Fm. Serra das Araras. Quase todas sondagens apresentam ramos terminais descendentes indicando a existência de um substrato regional mais condutor, suportando os pacotes arenosos.

Seções geoelétricas foram construídas a partir dos dados de resistividade, equidistantes em média de $8 \mathrm{~km}$. Ilustram a representação da estrutura geológica do aquífero (Figura 4). As seções longitudinais A-A' e B-B' combinadas foram confeccionadas a partir dos resultados obtidos de 9 e 10 sondagens elétricas, respectivamente, orientadas segundo a direção WSW-ENE (Figura 4A,B). Essas, em conjunto, mostram que a espessura do SAU varia de mais de 500 m nas vizinhanças da escarpa da Serra Geral de Goiás, a pouco mais de $100 \mathrm{~m}$ no extremo leste do perfil.

Como substrato do SAU meridional, têmse unidades condutoras, representadas pela sequência pelítica-carbonática do Grupo Bambuí. Já na porção extremo oriental (Figura 4-B,C), repousam sobre litologias mais resistivas, interpretado como o embasamento granito-gnáissico Arqueano-Paleoproterozoico do Complexo gnáissicomigmatítico de Correntina. Uma expressão da estrutura transversal (Figura 4-D) caracteriza provavelmente um hemi-gráben, com o pacote arenoso apresentando maiores espessuras no extremo oeste da sub-bacia e a presença de duas falhas com deslocamentos diferenciais estimados em 100 a $300 \mathrm{~m}$, ao longo do qual o substrato do Grupo Urucuia encontra-se soerguido.

Em todas as seções, observa-se que o nível freático varia de menos de $20 \mathrm{~m}$ nas proximidades dos vales, a mais de $180 \mathrm{~m}$ próximo a Serra Geral de Goiás, apresentando uma estreita relação com a topografia e revela a presença de um divisor do fluxo subterrâneo, separando o escoamento a leste em direção à bacia do rio São Francisco e a oeste em direção à bacia do rio Tocantins (Figura 4).

\section{Avaliação dos parâmetros hidrodinâmicos}

Os testes de aquífero surgiram principalmente da necessidade de se obter certas propriedades hidráulicas que avaliassem a disponibilidade de água subterrânea para os múltiplos usos. Dentre os principais métodos de interpretação úteis na determinação dos parâmetros hidrodinâmicos do SAU meridional, se destacam aqueles para aquíferos confinados não-drenante em regime transitório, desenvolvido por Theis (1935) e Cooper \& Jacob (1946), além do método de Neuman (1975), desenvolvido para avaliação de aquíferos livres. 
Caracterização geométrica e hidráulica do Sistema Aquífero Urucuia Meridional com base em testes de aquífero e levantamentos geofísicos elétricos

A A

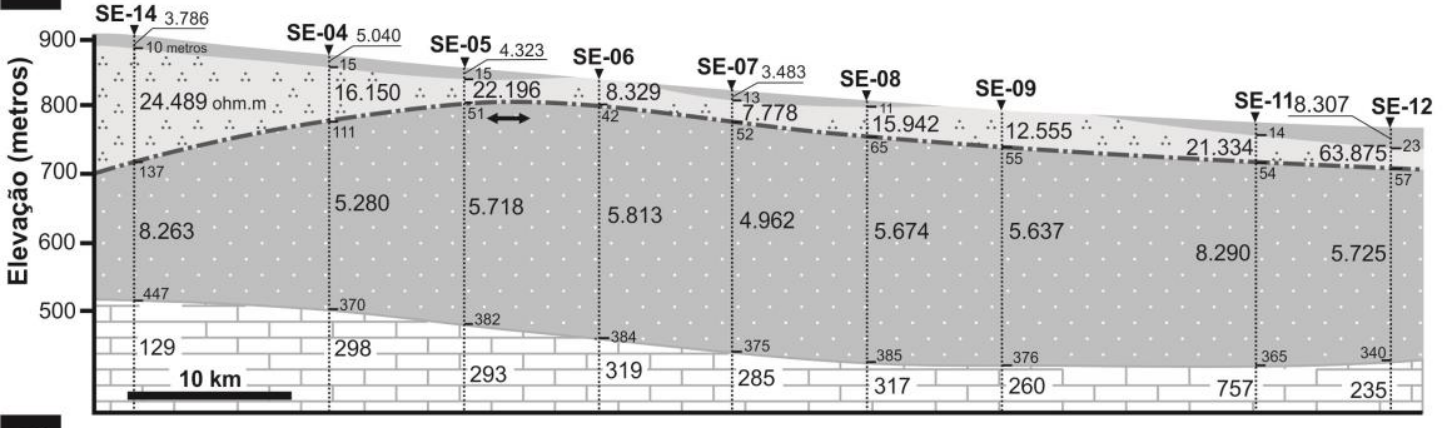

B
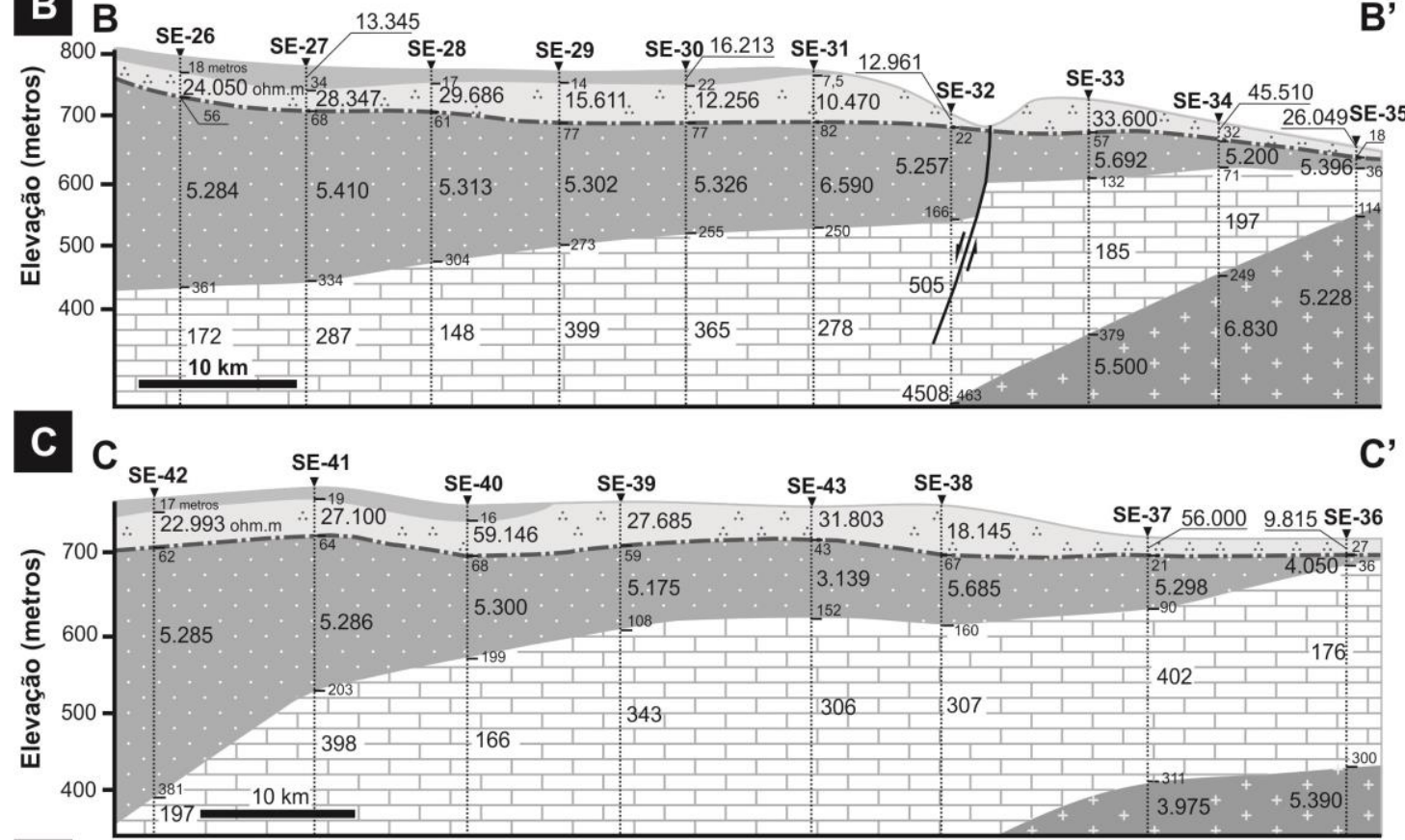

D D
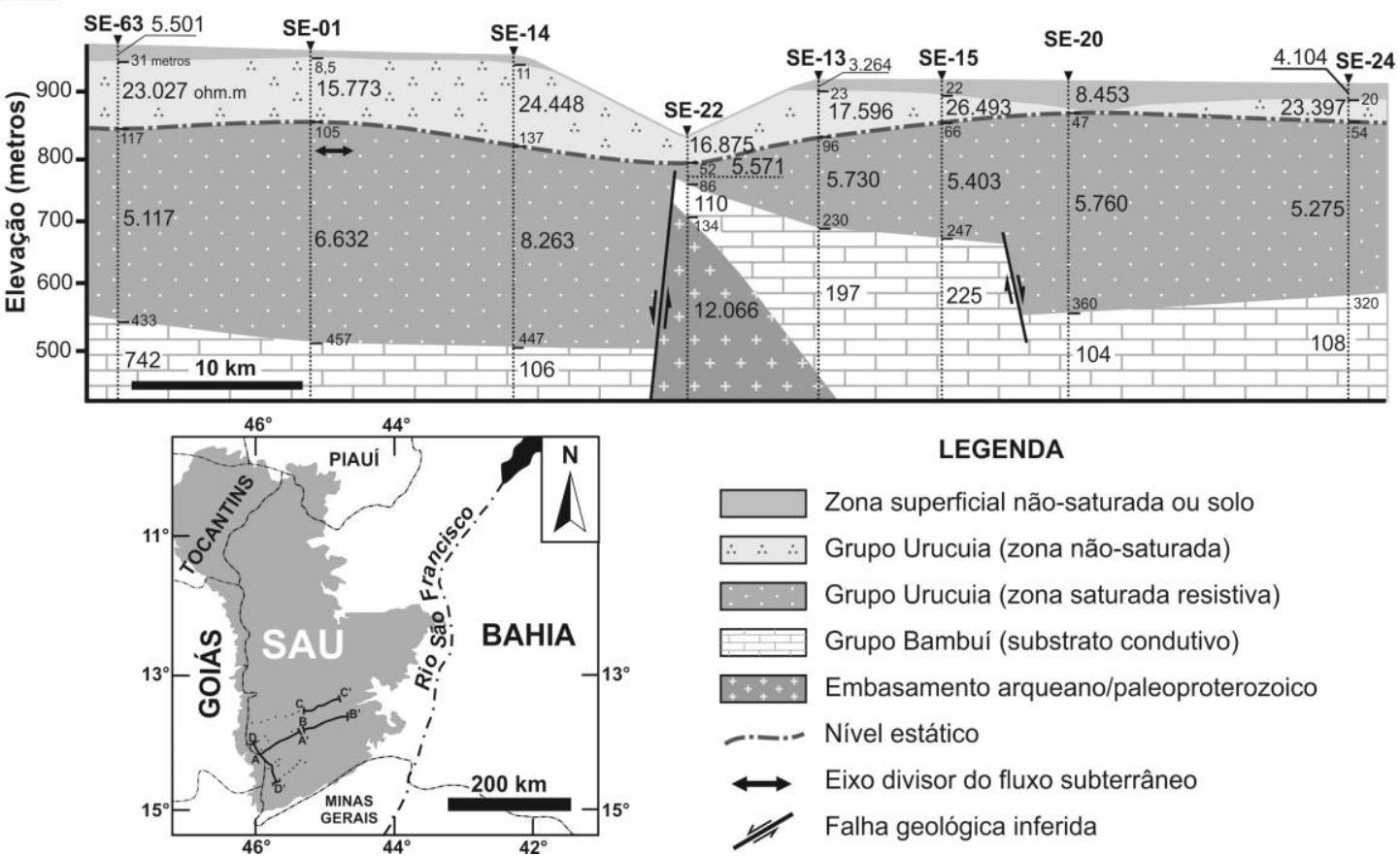

\section{LEGENDA}

Zona superficial não-saturada ou solo

Grupo Urucuia (zona não-saturada)

Grupo Urucuia (zona saturada resistiva)

Grupo Bambui (substrato condutivo)

\begin{tabular}{|l}
\hline+++ \\
\hline++
\end{tabular} Embasamento arqueano/paleoproterozoico

-.-. Nivel estático

$\longleftrightarrow$ Eixo divisor do fluxo subterrâneo

Falha geológica inferida

Figura 4 - Seções geoelétricas construídas com base nas sondagens elétricas indicadas (reinterpretado de Lima 2007)

Figure 4 - Geoelectrical sections constructed based on indicated electrical soundings (reinterpreted from Lima 2007) 


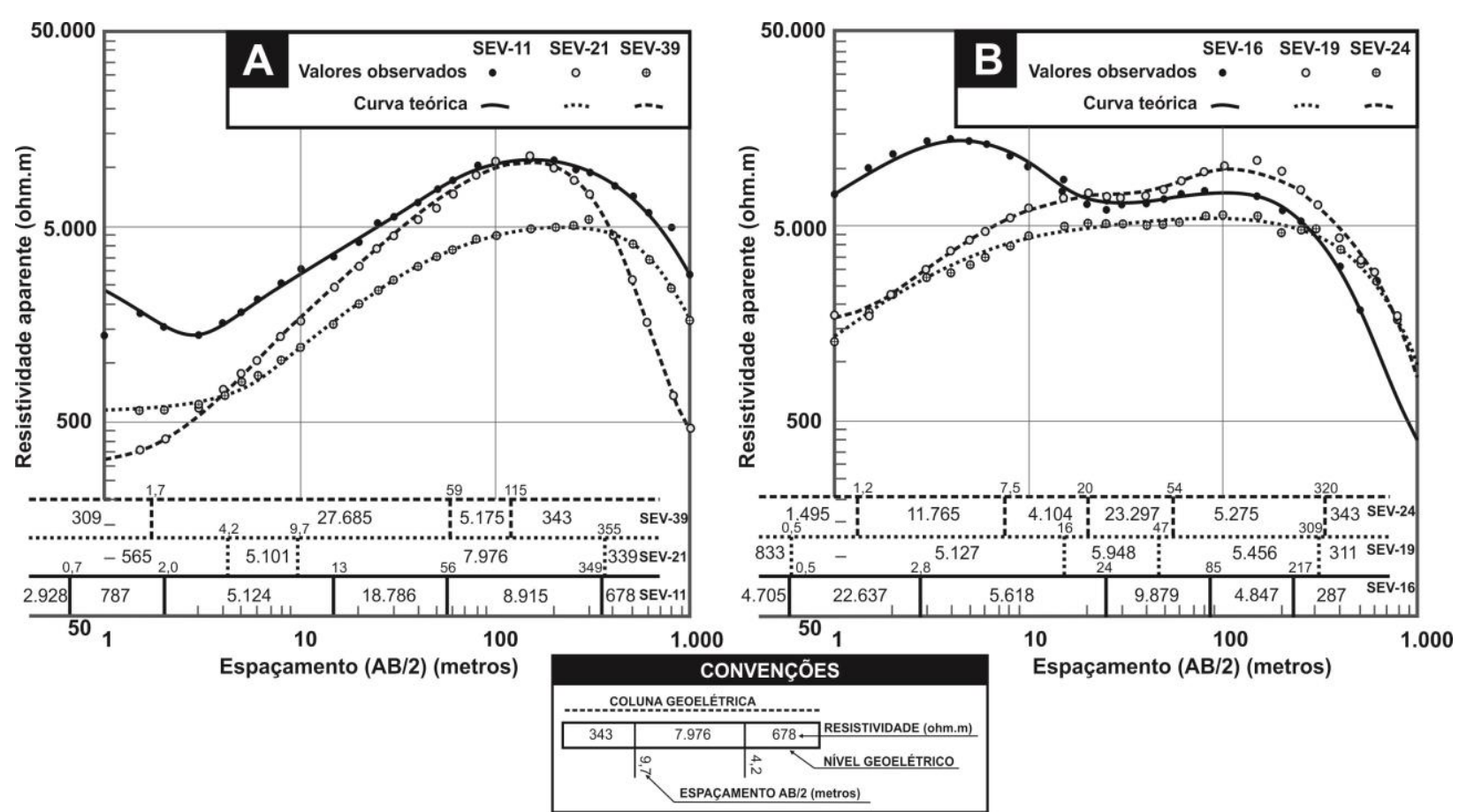

Figura 5 - Curvas geoelétricas representativas da área estudada exemplificando os procedimentos de ajuste e interpretação dos dados: A) (SE-11, SE-21, SE-39) e B) (SE-16, SE-19, SE-24) (modificado de Lima 2007)

Figure 5 - Geoelectrical curves representative of the studied area exemplifying the adjustment procedures and interpretation of data: A) (SE-11, SE-21, SE-39) and B) (SE-16, SE-19, SE-24) (modified from Lima 2007)

Na Figura 6 são apresentados os diagramas interpretativos dos testes de aquífero com base nos métodos de Theis (1935) e Neuman (1975), respectivamente. Os principais resultados obtidos revelam valores elevados de transmissividade $(T)$, variando de $10^{-1}$ a $10^{-2} \mathrm{~m}^{2} / \mathrm{s}$, condutividade hidráulica $(K)$, da ordem de $10^{-4} \mathrm{~m} / \mathrm{s}$ e coeficiente de armazenamento $(S)$, variando entre $10^{-4}$ e $10^{-5}$ para a unidade inferior associado a $\mathrm{Fm}$. Posse. Valores de $T$ da ordem de $10^{-4} \mathrm{~m}^{2} / \mathrm{s}, K$ em

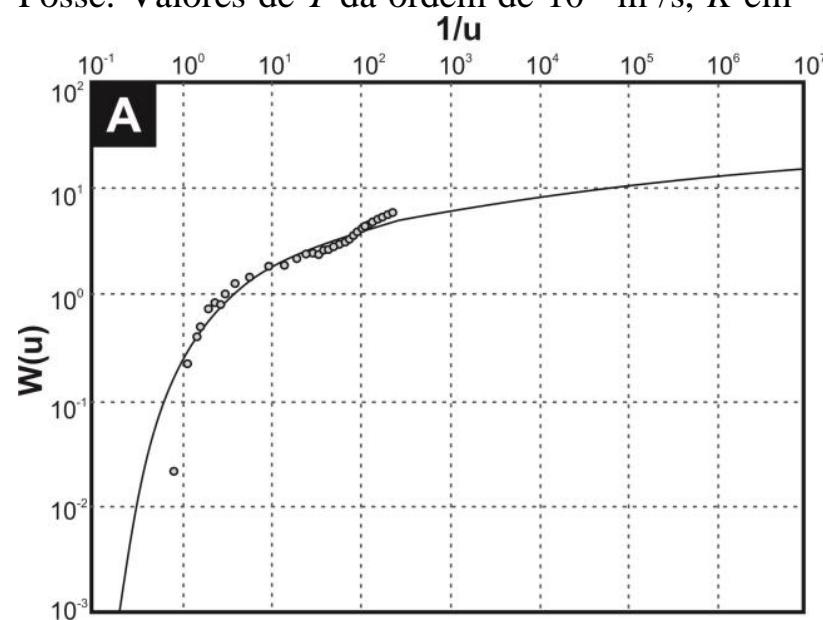

torno de $10^{-6} \mathrm{~m} / \mathrm{s}$ e $S$ da ordem de $10^{-2}$ para a unidade superior, representado pela Fm. Serra das Araras (Tabela 2). O valor de $S$ igual a $7,8 \times 10^{-6}$ não apresenta significado hidrogeológico, pois, tendo a recuperação do nível dinâmico, durante o teste, ocorrido num intervalo de 2 horas, a liberação da água nos primeiros instantes de bombeamento está associada à compactação do aquífero e expansão da água, comportamento semelhante a um aquífero confinado (Tabela 2).

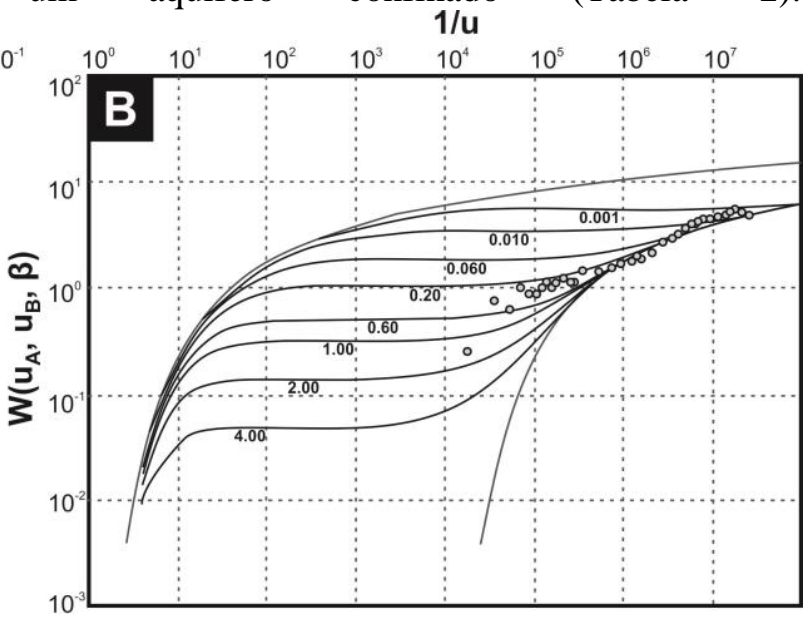

Figura 6 - Testes de aquífero realizados na fazenda COBA (A), interpretado pelo método de Theis (1935), e na fazenda Buriti (B), interpretado pelo método de Neuman (1975)

Figure 6 - Aquifer tests in the COBA farm (A), interpreted by the Theis method (1935), and Buriti farm (B), interpreted by Neuman method (1975) 
Tabela 2 - Sumário dos parâmetros hidrodinâmicos do Sistema Aquífero Urucuia, obtidos dos testes de aquífero realizados nas fazendas COBA* e Buriti**

Table 2 - Summary of Aquifer Urucuia System hydrodynamic parameters obtained from aquifer tests conducted in $\mathrm{COBA}^{*}$ and Buriti** farms.

\begin{tabular}{l|l|l|l|l|l|l}
\hline Localização & Unidade Aquífera & $\mathbf{Q} / \mathbf{s}\left(\mathbf{m}^{3} / \mathbf{h} / \mathbf{m}\right)$ & $\mathbf{T}\left(\mathbf{m}^{2} / \mathbf{s}\right)$ & $\mathbf{K}(\mathbf{m} / \mathbf{s})$ & $\mathbf{S}_{\boldsymbol{s}}$ & Método \\
\hline \hline $\begin{array}{l}\text { Bacia do Rio } \\
\text { Formoso* }\end{array}$ & \multirow{2}{*}{$\begin{array}{l}\text { Aquífero Confinado } \\
\text { (Fm. Posse) }\end{array}$} & 1078,4 & $7,6 \times 10^{-2}$ & $3,5 \times 10^{-4}$ & $2,4 \times 10^{-4}$ & Theis \\
\cline { 3 - 7 } & & 1078,4 & $2,2 \times 10^{-1}$ & $9,5 \times 10^{-4}$ & $5,1 \times 10^{-5}$ & $\begin{array}{l}\text { Theis } \\
\text { (recup.) }\end{array}$ \\
\hline \hline $\begin{array}{l}\text { Bacia do Rio } \\
\text { Arrojado** }\end{array}$ & \multirow{2}{*}{$\begin{array}{l}\text { Aquífero Livre (Fm. } \\
\text { Serra das Araras) }\end{array}$} & 0,65 & $5,2 \times 10^{-4}$ & $9,0 \times 10^{-6}$ & $5,0 \times 10^{-2}$ & Neuman \\
\cline { 5 - 7 } & & 0,65 & $8,4 \times 10^{-4}$ & $1,4 \times 10^{-6}$ & $7,8 \times 10^{-6}$ & $\begin{array}{l}\text { Neuman } \\
\text { (recup.) }\end{array}$ \\
\hline \hline
\end{tabular}

Onde: $\mathrm{Q} / \mathrm{s}$, capacidade específica; $\mathrm{T}$, transmissividade; $\mathrm{K}$, condutividade hidráulica; $\mathrm{S}_{\mathrm{s}}$, coeficiente de armazenamento específico; Recup, recuperação.

Os parâmetros hidrogeológicos regionais (Tabela 1) (SCHUSTER et al., 2002; SCHUSTER et al., 2003; NASCIMENTO, 2003; GASPAR \& CAMPOS, 2007; GASPAR, 2006) indicam que os arenitos no domínio do SAU apresentam dois tipos de porosidade, representando diferentes unidades aquíferas, a saber: (i) aquíferos com porosidade primária intergranular associado aos arenitos finos, homogêneos, avermelhados e friá- veis da Fm. Posse e às sequências de conglomerados, arenitos e siltitos da Fm Serra das Araras, compartimentados por (ii) aquitarde com porosidade por fratura, representado pelos níveis de arenitos silicificados impermeáveis e fraturados da Fm. Serra das Araras, de espessura variável e responsáveis pelo retardamento da drenagem vertical da água de recarga e confinamento do SAU em profundidade (Figura 7).

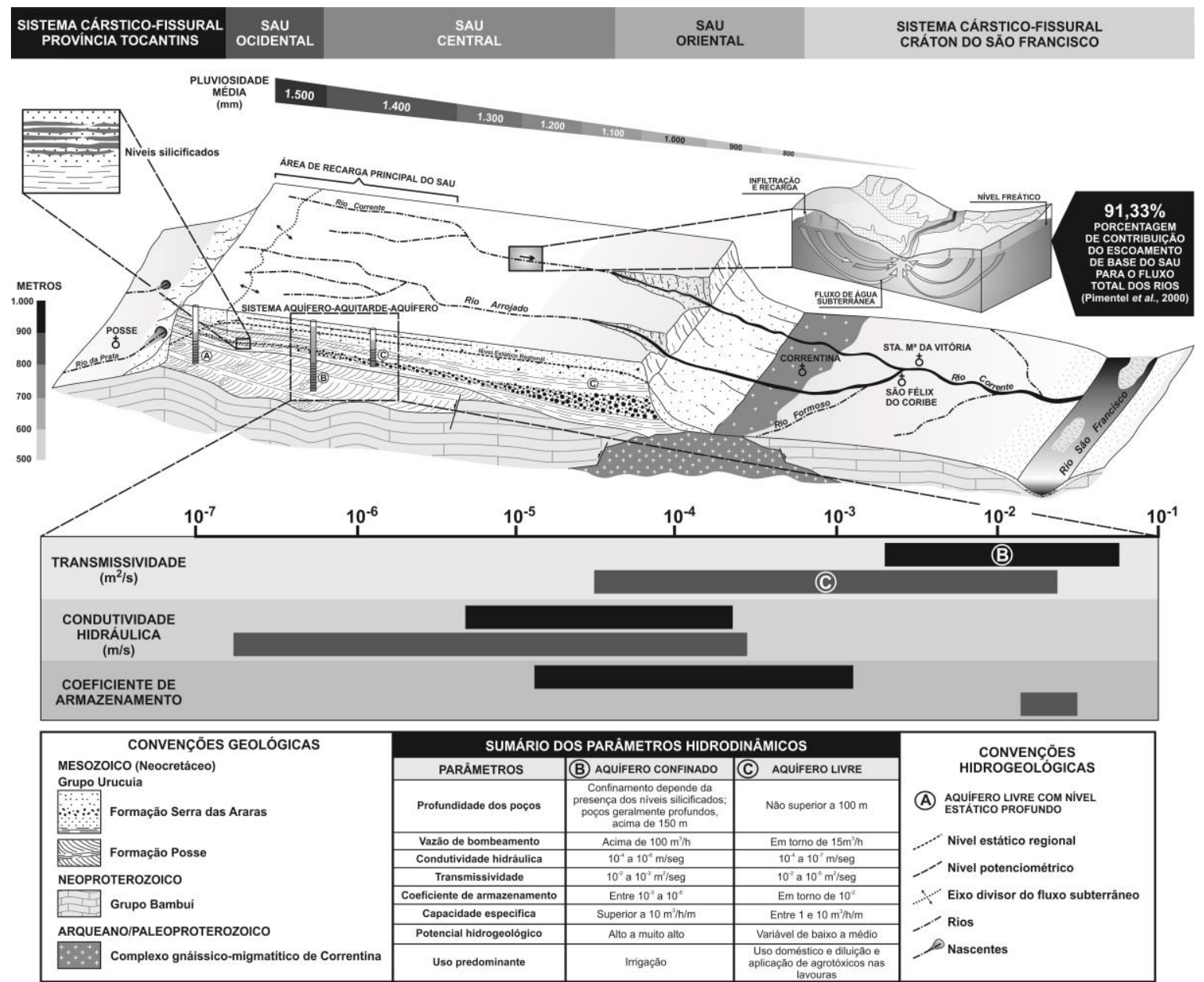

Figura 7 - Representação esquemática da hidrodinâmica associada aos aspectos geológicos/geofísicos da área estudada

Figure 7 - Schematic representation of the hydrodynamics associated with geological/geophysical aspects of the studied area 


\section{CONSIDERAÇÕES FINAIS}

Nas bacias hidrográficas dos rios Formoso e Arrojado, os testes de aquífero e levantamentos geofísicos elétricos revelam que o SAU meridional comporta-se como um sistema aquíferoaquitarde-aquífero, representado pela Fm. Serra das Araras, níveis silicificados fraturados e Fm. Posse, respectivamente. A presença de subtipos de aquíferos se deve às variações hidrodinâmicas e litológicas do Grupo Urucuia.

Do ponto de vista geométrico, os dados geoelétricos permitem caracterizar a estrutura regional do SAU, expressa na forma de um hemigráben, composto predominantemente por arenitos, com espessuras variando de mais de $500 \mathrm{~m}$ no extremo oeste e diminuindo progressivamente à medida que alcança a porção oriental. Os níveis estáticos variam de menos de $20 \mathrm{~m}$ nas proximidades dos vales a mais de 180 metros próximo ao limite físico da Serra Geral de Goiás. Neste último, os poços apresentam níveis estáticos profundos, fruto de um divisor de águas subterrâneas, que tem o seu fluxo de base contribuindo para a alimentação dos rios do sistema cárstico-cristalino da bacia do rio Tocantins, a oeste, e da bacia do rio São Francisco, a leste.

Os resultados dos levantamentos de campo, perfis lito-estratigráficos dos poços e o cálculo dos parâmetros hidrodinâmicos T, K e S indicam a existência de duas unidades aquíferas principais

\section{REFERÊNCIAS}

Amorim Júnior V.; Lima, O.A.L. Avaliação hidrogeológica do aquífero Urucuia na bacia do rio das Fêmeas usando resistividade e polarização elétrica induzida. Revista Brasileira de Geofísica. 25(2): 117-129. 2007.

Anderson M.P.; Woessner W.W. Applied groundwater modeling: simulation of flow and advective transport. Academic Press, New York, 381p. 1992.

Aquino R.F.; Nascimento K.R.F.; Rodrigues, Z.R.; Vieira C.; Maia P.H.P.; Costa A.B. Caracterização hidrogeoquímica e isotópica das águas superficiais e subterrâneas do Oeste baiano - bacia do rio das Fêmeas - Bahia. Relatório Técnico. Salvador-BA: 2003. Superitendência dos Recursos Hídricos (SRH), $20 \mathrm{p}$.

Bonfim L.F.C.; Gomes R.A.A. D. Aquífero Urucuia Geometria e Espessura: Idéias para Discussão. In: Congresso Brasileiro de Águas Subterrâneas, XX, 2004, Cuiabá (MT), Anais. 1 CD-ROM.

Borges M.S.; Igreja H.L.S.; Costa J.B.S.; Hasui Y. Faciologia e Tectônica da Formação Urucuia na Região de Dianópolis, Sudeste do Estado do Tocantins. Geociências, São Paulo, 11(1): 7-18. 1992. no SAU meridional: uma inferior, do tipo confinado, representado pela Fm. Posse, onde a compactação do aquífero e a descompressão da água são os principais mecanismos de liberação da água subterrânea, que ocorre devido à diminuição da pressão hidrostática devido ao bombeamento. Esta unidade apresenta poços produtores utilizados em projetos de irrigação em pivôs centrais, com vazões de explotação acima de $300 \mathrm{~m}^{3} / \mathrm{h}$, pequenos rebaixamentos observados nos poços, raios de influência extensos (acima de $2.500 \mathrm{~m}$ ) e alto potencial hidrogeológico.

A presença dos níveis silicificados, fraturados e impermeáveis limita e confina a unidade inferior e, provavelmente, possibilita uma drenança ascendente para a unidade aquífera superior, do tipo livre, representado pela Fm. Serra das Araras, onde a água é liberada predominantemente pela drenagem gravitativa dos poros, com uma pequena participação da compactação do aquífero e descompressão da água nos instantes iniciais de bombeamento. É responsável pela perenidade e elevada vazão específica da rede de drenagem nos momentos de estresse hídrico. A água extraída dessa unidade é utilizada principalmente para uso doméstico e na diluição e aplicação de agrotóxicos nas lavouras, através de poços com vazões de explotação em torno de $15 \mathrm{~m}^{3} / \mathrm{h}$.

Campos J.E.G.; Dardenne M.A. Estratigrafia e sedimentação da bacia Sanfranciscana: uma revisão. Revista Brasileira de Geociências, 27: 269-282. 1997a.

Campos J.E.G.; Dardenne M.A. Origem e evolução tectônica da bacia Sanfranciscana. Revista Brasileira de Geociências, 27: 283-294. 1997b.

Campos J.E.G.; Dardenne M.A. Distribuição, estratigrafia e sistemas deposicionais do Grupo Urucuia - Cretáceo Superior da Bacia Sanfranciscana. Geociências, São Paulo, 18(2): 481-499. 1999.

Cooper H.H.; Jacob C.E. A generalized graphical method for evaluating formation constants and summarizing well-field history. Transactions, American Geophysical Union. 27: 526-534. 1946.

Gaspar M.T.P. Sistema Aquífero Urucuia: Caracterização Regional e Propostas de Gestão. Brasília-DF. 2006. 158p. Tese de doutorado $n^{\circ} 76$. IG-UnB.

Gaspar M.T.P.; Campos J.E.G. O Sistema Aquífero Urucuia. Revista Brasileira de Geociências, 37(4): 216-226. 2007. 
Gaspar M.T.P.; Campos J.E.G.; Moraes R.A.V de. Determinação das espessuras do Sistema Aquífero Urucuia a partir de estudo geofísico. Revista Brasileira de Geociências, 42 (Suppl 1): 154-166. 2012.

Koefoed O. Resistivity Sounding Measurements: Geosounding Principles. Methods in Geochemistry and Geophysics. Elsevier, Amsterdam, 276p. 1979.

Lima O.A.L. Estudos geológicos e geofísicos do Aquífero Urucuia na Bacia do Rio Cachorro - Oeste do Estado da Bahia. Relatório técnico. Salvador-BA: 2000. Superintendência de Recursos Hídricos- SRH/ Centro de Pesquisas em Geofísica e Geologia-CPGG/UFBA. $42 p$.

Lima O.A.L. Levantamentos Geofísicos no Aquífero Urucuia: Sub-bacias dos Rios Formoso e Arrojado, Bahia. Relatório técnico. Salvador-BA: 2007. Universidade Federal da Bahia/ Centro de Pesquisas em Geofísica e Geologia- CPGG/UFBA. 37p.

Nascimento K.R.F. (coord.). Uso conjunto das águas superficiais e subterrâneas da sub-bacia do rio das Fêmeas- Bahia. Relatório Final. Salvador- BA: 2003. ANA/ GEF/PNUMA/OEA, Superintendência de Recursos Hídricos (SRH). 208p.

Neuman S.P. Analysis of pumping test data from anisotropic unconfined aquifer considering delayed gravity response. Water Resources Research, 11:329-342. 1975.

Pimentel A.L.; Aquino R.F.; Silva R.C.A.; Vieira C.M.B. Estimativa da recarga do aquífero Urucuia da subbacia do rio das Fêmeas - Oeste da Bahia, utilizando separação de hidrogramas. In: $1^{\circ}$ Congresso sobre aproveitamento e gestão de recursos hídricos em países de idioma português, 2000, Rio de Janeiro - RJ, $11 \mathrm{p}$.
Schuster H.D.M.; Silva F.F.; Teixeira S.L.; Batista L.H.G.; Freitas W.A. Estudos hidrogeológicos do aquífero Urucuia no Oeste baiano para obtenção de parâmetros nas outorgas de mananciais subterrâneos. In: XII Congresso Brasileiro de Águas Subterrâneas, 2002, Florianópolis-SC. 15p.

Schuster H.D.M.; Silva F.F.; Araújo H.D.B. Modelagem do fluxo subterrâneo com vistas a definição dos parâmetros para outorga de mananciais subterrâneos na bacia hidrográfica do rio do Cachorro - Oeste do Estado da Bahia. Relatório Parcial $n^{\circ} 1$. UFPB. Campina Grande-PB: 2003. 13p.

Sgarbi G.N.C. Geologia da Formação Areado. Cretáceo Inferior a Médio da Bacia Sanfranciscana, Oeste do estado de Minas Gerais. Rio de Janeiro (RJ). 1989. 324p. Dissertação de Mestrado. Universidade Federal do Rio de Janeiro.

Spigolon A.L.D.; Alvarenga C.J.S. de. Fáceis e elementos arquiteturais resultantes de mudanças climáticas em um ambiente desértico: Grupo Urucuia (Neocretáceo), Bacia Sanfranciscana. Revista Brasileira de Geociências, 32(4): 579-586. 2002.

Theis C.V. The lowering of the piezometer surface and the rate and discharge of a well using groundwater storage. Transactions, American Geophysical Union. 16: 519-524. 1935.

Tschiedel M.W. Aplicação de estudo geofísico como contribuição ao conhecimento da tectônica da SubBacia Urucuia. Brasília-DF, 2004. 76p. Dissertação de Mestrado, Instituto de Geociências da Universidade de Brasília.

Vozoff K. Numerical resistivity analysis: Horizontal Layers. Geophysics 23: 536-556. 1958. 